Article

\title{
Structural Elucidation and Cytotoxicity of a New 17-Membered Ring Lactone from Algerian Eryngium campestre
}

\author{
Ali Medbouhi ${ }^{1,2}$, Aura Tintaru ${ }^{3, *}$, Claire Beaufay ${ }^{4}{ }^{\complement}$, Jean-Valère Naubron ${ }^{5}$, Nassim Djabou ${ }^{1}$, \\ Jean Costa ${ }^{2}$, Joëlle Quetin-Leclercq ${ }^{4}$ and Alain Muselli ${ }^{2, *}$ \\ 1 Laboratoire de Chimie Organique Substances Naturelles et Analyses (COSNA), Département de Chimie, \\ Faculté des Sciences, Université de Tlemcen, BP 119, Tlemcen 13000, Algeria; sm-ali13@hotmail.fr (A.M.); \\ n_djabou@mail.univ-tlemcen.dz (N.D.) \\ 2 Laboratoire Chimie des Produits Naturels (CPN), Campus Grimaldi, Université de Corse, UMR CNRS 6134 \\ SPE, BP 52, 20250 Corte, France; costa@univ-corse.fr \\ 3 Aix Marseille Univ, CNRS, Institut de Chimie Radicalaire, UMR 7273, 13397 Marseille, France \\ 4 UCLouvain, Louvain Drug Research Institute, Pharmacognosy Group, Avenue E. Mounier, 72, bte B1.7203, \\ B-1200 Bruxelles, Belgium; claire.beaufay@uclouvain.be (C.B.); joelle.leclercq@uclouvain.be (J.Q.-L.) \\ 5 Centrale Marseille, Aix Marseille Univ, CNRS, FSCM, Spectropole, Marseille 13397, France; \\ jean-valere.naubron@univ-amu.fr \\ * Correspondence: aura.tintaru@univ-amu.fr (A.T.); muselli_a@univ-corse.fr (A.M.); \\ Tel.: +33-491-288629 (A.T.); Tel.: +33-495-450171 (A.M.)
}

Received: 10 November 2018; Accepted: 6 December 2018; Published: 8 December 2018

\begin{abstract}
The chemical composition of a hexanic extract of Eryngium campestre, obtained from its aerial parts, was investigated by GC-FID, GC/MS, HRMS, NMR and VCD analyses. The main compounds were germacrene D (23.6\%), eudesma-4(15)-7-dien-1- $\beta$-ol (8.2\%) and falcarindiol (9.4\%), which are associated with a new uncommon and naturally found 17-membered ring lactone. This 17-membered ring features conjugated acetylenic bonds, named campestrolide (23.0\%). The crude extract showed moderate antitrypanosomal (Trypanosoma brucei brucei), antileishmanial (Leishmania mexicana mexicana) and anticancer (cancerous macrophage-like murine cells) activities, and also displayed cytotoxicity, (human normal fibroblasts) in similar concentration ranges $\left(\mathrm{IC}_{50}=3.0,3.9,4.0\right.$ and $4.4 \mu \mathrm{g} / \mathrm{mL}$

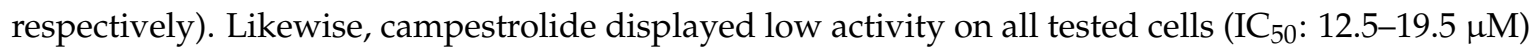
except on Trypanosoma, on which it was very active and moderately selective $\left(\mathrm{IC}_{50}=2.2 \mu \mathrm{M}\right.$. SI= 8.9). In conclusion, the new compound that has been described, displaying a singular structure, possesses interesting antitrypanosomal activity that should be further investigated and improved.
\end{abstract}

Keywords: Eryngium campestre; 17-membered ring lactone; cytotoxicity; Trypanosoma; Leishmania

\section{Introduction}

The genus Eryngium, the most common of the Apiaceae family, comprises more than 250 species with cosmopolitan distribution in temperate regions of all continents, mainly in Eurasia, North Africa and South America [1]. This genus has been the subject of several phytochemical investigations. A remarkable richness in natural chemicals with interesting bioactivities was reported in the literature: terpenoids, polyacetylenes, saponins, steroids and phenolics (such as, flavonoids and coumarins) [2]. This phytochemical diversity can explain the large traditional uses of many Eryngium species in the treatment of emetic and gastrointestinal infections [3], several types of inflammatory disorders [4] and various parasitic infections [5]. More traditional uses of many Eryngium species include use in antidotes 
for poisons, hypoglycemic agents [6], diarrhea remedies, stimulants, aphrodisiacs, antitussives and diuretics [7].

Among this large variety of species is the E. campestre species (Figure 1), which is a perennial plant that measures from 30 to $60 \mathrm{~cm}$ in length. This species is widespread in Western and Central Europe, North Africa, the Middle East and the Caucasus [8]. The plant has been used in European herbal medicine as an infusion for the treatment of whooping cough, as well as in the treatment of kidney and urinary tract inflammations [9].

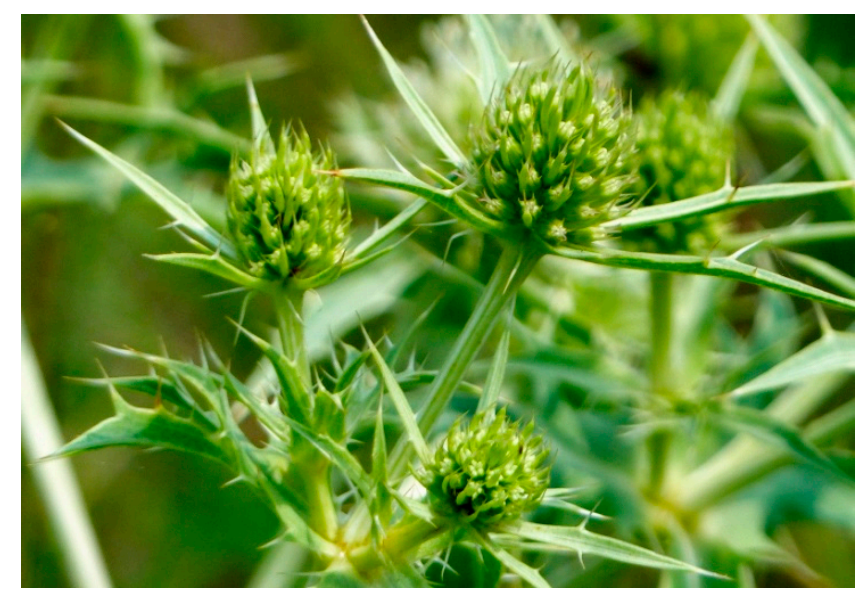

Figure 1. Aerial parts of Erygium campestre.

Many compounds belonging to different phytochemical classes were already identified in this plant. Some of these were flavonoids and flavonoacyl derivatives, extracted from the aerial parts and the roots [10-12]; monoterpene glycosides with cyclohexanone moiety [13]; and a coumarin derivative [14] and triterpene saponins were found in the roots [15]. E. campestre essential oils displayed a complex chemical composition with hydrocarbon and oxygenated sesquiterpenes. The main components were germacrene $D, \beta$-curcumene, $(E)$ - $\beta$-farnesene, spathulenol, $\alpha$-bisabolol and $\alpha$-cadinen-15-al [16,17].

E. campestre has been the subject of many biological investigations. The methanol extracts from the aerial parts showed very strong antitumoral activity on potatoes' tumor cells induced by Agrobacterium tumefaciens (ATCC 23341), but no significant antimicrobial activity [18]. The flavonol-rich methanol extracts of E. campestre aerial parts exhibited moderate to strong antioxidant activity in DPPH radical scavenging and reducing power assays; in contrast, no effect on Alzheimer's disease was reported [19]. Ethanol extracts, obtained from the aerial parts and the roots, revealed noticeable anti-inflammatory and antinociceptive activities [20].

Protozoan neglected diseases, such as African trypanosomiasis and cutaneaous leishmaniasis, are tropical infections affecting more than one billion people worldwide and lacking financial investments. The current available treatments suffer from some toxicity, administration difficulty and even resistance development. In this area, the plants and their bioactive secondary metabolites constitute a potential source of crucially needed new and effective drugs [21,22].

As part of our research work on bioactive metabolites from Algerian plants, phytochemical investigation of the hexane extracts obtained from the E. campestre aerial parts was performed. This study describes the isolation and structural elucidation of a new 17-membered ring lactone using chromatography techniques (GC-FID, GC-MS), HRMS, 1D and 2D NMR experiments and circular dichroism, along with two known polyacetylenes: falcarinol and falcarindiol. The cytotoxicity and some antiprotozoal activities of the bulk extract and the newly isolated macrocyclic lactone were then investigated in vitro, in order to evaluate their potential pharmacological properties. 


\section{Results and Discussion}

\subsection{Chemical Composition}

The analysis of the filtered hexane extract of the E. campestre (HEEC) aerial parts using hyphenated methods allowed the identification of 34 components, which accounted for $84.0 \%$ of the total composition (Table 1). The chemical composition was dominated by the oxygenated compounds (52.8\%). The principal classes were sesquiterpenes (48.6\%) and polyacetylenes (35.2\%). Hydrocarbon compounds were exclusively represented by sesquiterpenes $(31.2 \%)$. The main components were germacrene D 9 (23.6\%), unknown compounds 33 (23.0\%), 34 (9.4\%), eudesma-4(15)-7-dien-1- $\beta$-ol $27(8.2 \%)$ and falcarinol $32(2.8 \%)$. Thirty-two components were identified by comparison of their RI and MS data with those from our home library, "Arômes". The spectrometric data of $\mathbf{3 3}$ and $\mathbf{3 4}$ were not found in our MS-library. Their identifications were achieved after purification by column chromatography, using a combination of analytical techniques: GC-FID, GC/MS-EI, HRMS, exhaustive NMR characterization and VCD. The structures of the main components that were identified are presented in Figure 2. The structure elucidation of $\mathbf{3 3}$ will be presented and discussed separately.<smiles>C=C(/C=C\C(CC/C=C(/C)CCC)C(C)C)CC</smiles>

9 Germacrene D<smiles>C=C1CC[C@@H](O)[C@]2(C)CC=C(C(C)C)C[C@H]12</smiles>

27 Eudesma-4(15)-7-dien-1- $\beta$-ol

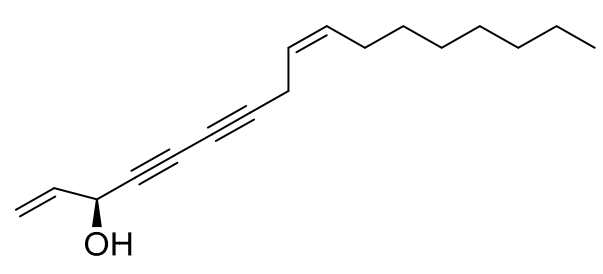

32 Falcarinol

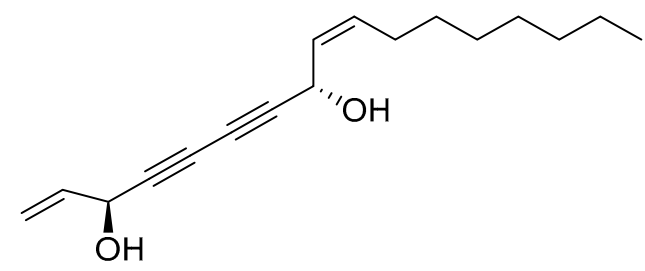

34 Falcarindiol

Figure 2. The main components identified in the hexane extract of E. campestre, from Algeria.

Table 1. The chemical composition of the hexane extract of Eryngium campestre (HEEC).

\begin{tabular}{ccccccc}
\hline No. & Components $^{\mathbf{a}}$ & LRIa $^{\mathbf{b}}$ & $\mathbf{R i a}^{\mathbf{c}}$ & $\mathbf{R I p}^{\mathbf{d}}$ & HEEC $^{\mathbf{e}}$ & Identification $^{\mathbf{f}}$ \\
\hline 1 & $\alpha$-Copaene & 1379 & 1375 & 1438 & 0.4 & RI, MS \\
2 & $\beta$-Bourbonene & 1385 & 1383 & 1515 & 0.1 & RI, MS \\
3 & $\beta$-Elemene & 1388 & 1387 & 1589 & 0.5 & RI, MS \\
4 & $\beta$-Ylangene & 1420 & 1416 & 1562 & 0.6 & RI, MS \\
5 & $\beta$-Copaene & 1431 & 1432 & 1581 & 0.2 & RI, MS \\
6 & Alloaromadendrene & 1451 & 1454 & 1631 & $\operatorname{tr}$ & RI, MS \\
7 & diepi-4,5-Aristolochene & 1467 & 1465 & 1665 & 0.4 & RI. MS \\
8 & $\alpha$-Curcumene & 1470 & 1471 & 1742 & 1.0 & RI, MS \\
9 & Germacrene D & $\mathbf{1 4 7 6}$ & $\mathbf{1 4 8 0}$ & $\mathbf{1 7 0 4}$ & $\mathbf{2 3 . 6}$ & RI, MS \\
10 & $\beta$-Selinene & 1483 & 1484 & 1712 & 0.8 & RI, MS \\
11 & $\alpha$-Muurolene & 1496 & 1503 & 1720 & 0.2 & RI, MS \\
12 & $\beta$-Bisabolene & 1500 & 1500 & 1720 & 1.2 & RI, MS \\
13 & Sesquicineole & 1505 & 1506 & 1737 & 1.1 & RI, MS \\
14 & $\tau$-Cadinene & 1507 & 1509 & 1752 & 0.2 & RI, MS \\
15 & $\beta$-Curcumene & 1509 & 1510 & 1733 & 0.5 & RI, MS \\
16 & -Cadinene & 1516 & 1514 & 1752 & 1.0 & RI, MS \\
17 & $\alpha$-Cadinene & 1535 & 1533 & 1743 & 0.1 & RI, MS \\
18 & 1,5 -Epoxysalvial4(14)-ene & 1545 & 1548 & 1941 & 0.8 & RI, MS \\
\hline
\end{tabular}


Table 1. Cont.

\begin{tabular}{|c|c|c|c|c|c|c|}
\hline No. & Components $^{\mathrm{a}}$ & $\operatorname{LRIa}^{b}$ & $\operatorname{Ria}^{c}$ & RIp $^{d}$ & HEEC $^{\mathrm{e}}$ & Identification $^{f}$ \\
\hline 19 & Germacrene B & 1553 & 1551 & 1827 & 0.4 & RI, MS \\
\hline 20 & Spathulenol & 1563 & 1562 & 2103 & 1.3 & RI, MS \\
\hline 21 & $\beta$-Copaene-4- $\alpha$-ol & 1575 & 1573 & 2141 & 1.0 & RI, MS \\
\hline 22 & Salvial-4(14)-en-1-one & 1583 & 1585 & 2005 & 0.5 & RI, MS \\
\hline 23 & Ledol & 1600 & 1602 & 2030 & 0.8 & RI, MS \\
\hline 24 & $\tau$-Cadinol & 1632 & 1638 & 2169 & 0.9 & RI, MS \\
\hline 25 & $\alpha$-Cadinol & 1645 & 1645 & 2231 & 1.6 & RI, MS \\
\hline 26 & $\alpha$-Bisabolol & 1663 & 1672 & 2199 & 0.7 & RI, MS \\
\hline 27 & Eudesma-4(15)-7-dien-1- $\beta$-ol & 1681 & 1667 & 2333 & 8.2 & RI, MS \\
\hline 28 & 14-hydroxy- $\alpha$-Muurolene & 1755 & 1755 & 2599 & 0.3 & RI, MS \\
\hline 29 & 14-hydroxy- $\tau$-Cadinene & 1788 & 1784 & 2607 & 0.2 & RI, MS \\
\hline 31 & Hexadecanoic acid & 1942 & 1941 & 2930 & 0.2 & RI, MS \\
\hline 32 & Falcarinol & 2028 & 2026 & - & 2.8 & RI, MS, [23] \\
\hline 33 & Campestrolide & - & 2143 & 2970 & 23.0 & RI, MS, NMR \\
\hline 34 & Falcarindiol & $2190 \mathrm{~g}$ & 2164 & - & 9.4 & RI, MS, NMR \\
\hline \multicolumn{4}{|c|}{ Total identification (\%) } & & 84.0 & \\
\hline \multicolumn{4}{|c|}{ Hydrocarbon compounds } & & 31.2 & \\
\hline \multicolumn{4}{|c|}{ Oxygenated compounds } & & 52.8 & \\
\hline \multicolumn{4}{|c|}{ Hydrocarbon sesquiterpenes } & & 31.2 & \\
\hline \multicolumn{4}{|c|}{ Oxygenated sesquiterpenes } & & 17.4 & \\
\hline \multicolumn{4}{|c|}{ Non terpenic compounds } & & 3.0 & \\
\hline
\end{tabular}

${ }^{a}$ Elution order is given on the apolar column (Rtx-1). In bold are the main compounds. ${ }^{b}$ Retention indices from the literature [24] are on the apolar column, except for 34 [25] (IRIa). ${ }^{c}$ Retention indices are on the apolar Rtx-1 column (RIa). ${ }^{d}$ Retention indices are on the polar Rtx-Wax column (RIp). ${ }^{\text {e }}$ HEEC: Hexane extract of Eryngium triquetrum. The relative percentages of the extract constituents were calculated from the GC peak areas, without application of correction factors. $\operatorname{tr}=$ trace $(<0.05 \%) . \%$ : Percentages are given on the apolar column, except for components with identical RIa (in such cases, percentages are given on the polar column). ${ }^{\mathrm{f}}$ RI: Retention Indices; MS: Electron Impact Mass Spectrometry; ${ }^{\mathrm{g}}$ The reported value was determined on a different apolar column [25], which would explain the significant difference as compared to our measurement.

\subsection{Identification of Compounds Not Present in MS-Libraries}

Column chromatography was carried out using a gradient of polarity with hexane and diisopropyl ether and then followed by UV detection, producing 75 fractions from the hexane extract of E. campestre. Among them, 34 (8 mg of an almost pure sample) was isolated in the fraction F34 obtained with diisopropyl ether/hexane (10/100). EI mass spectra of 34 exhibited a base peak at $m / z 129$ and a signal at $m / z 260$, which could be attributed to the molecular ion. ESI (+)-HRMS measurement confirms the molecular formula of $\mathrm{C}_{17} \mathrm{H}_{24} \mathrm{O}_{2}$ (detected ion $\mathrm{C}_{17} \mathrm{H}_{24} \mathrm{O}_{2} \mathrm{Na}^{+}(\mathrm{m} / z)$ experimental 283.1668 and $(\mathrm{m} / z)_{\text {theoretic }}$ 283.1667; error $+0.4 \mathrm{ppm}$ ). Additionally, the acquired ${ }^{13} \mathrm{C}-\mathrm{NMR}$ spectra showed the presence of both oxygenated $s p^{3}$ methyne groups detected at $63.50 \mathrm{ppm}$ and $58.61 \mathrm{ppm}$, respectively, and four $s p$ carbon atoms detected between $79.86 \mathrm{ppm}$ and $68.69 \mathrm{ppm}$. These observations lead us to an oxygenated polyacetylene skeleton, a derivative of falcarinol 32. A comparison of mass spectra and NMR data in the literature [26] allowed the identification of falcarindiol (Figure 2-34). This polyacetylenic compound, accounting for $9.4 \%$ of the E. campestre hexane extract, is a main component of the roots of Angelica japonica [26], Daucus carota [27], and Petroselinum crispum [Mill.] Nym. ssp. tuberosum [25]. Its identification in the Eryngium species was first reported by Bohlmann and Zdero [28] in ether extracts of E. alpinum, E. coeruleum and E. giganteum. However, this is the first time it has been identified in E. campestre. Falcarindiol has been shown to have anti-inflammatory, antibacterial and anticancer activities, as well as protective effects against hepatotoxicity $[29,30]$.

Column chromatography using the gradient of solvent diisopropyl ether/hexane (5/95) produces a yellow, odorous, oily compound (F21: $13 \mathrm{mg}, 33$ at 96\%). GC/MS-EI spectra of 33 exhibited an isotopic cluster at $m / z 270$ and 271 , and a base peak at $m / z 115$. Other fragment ions were observed at $m / z$ 55, 91, 128 and 145 (Figure 3). The ESI (+)-HRMS measurement performed on 33 reveals the elemental composition of $\mathrm{C}_{18} \mathrm{H}_{22} \mathrm{O}_{2}$ (detected ion: $\mathrm{C}_{18} \mathrm{H}_{22} \mathrm{O}_{2} \mathrm{Na}^{+}$: $(m / z)$ experimental 293.1513 and 
$(\mathrm{m} / \mathrm{z})_{\text {theoretic }}$ 293.1512. error $\left.+0.3 \mathrm{ppm}\right)$, which would correspond to a compound possessing an additional carbon atom and one supplementary unsaturation (DBE: double bounds equivalent $=8$ ) as compared to the falcarindiol $34\left(\mathrm{C}_{17} \mathrm{H}_{24} \mathrm{O}_{2}, \mathrm{DBE}=7\right)$. The IR spectrum exhibits absorption peaks at $1739 \mathrm{~cm}^{-1}, 1098 \mathrm{~cm}^{-1}$ and $1225 \mathrm{~cm}^{-1}$, corresponding to $\mathrm{C}=\mathrm{O}$ and $\mathrm{C}-\mathrm{O}$ vibrations. This indicates the presence of a cyclic lactone function. Additionally, absorption bands at $2255 \mathrm{~cm}^{-1}$ and $2856-2928 \mathrm{~cm}^{-1}$ indicated the presence of $\mathrm{C} \equiv \mathrm{C}$ and $\mathrm{CH}_{2}$ bonds, respectively.

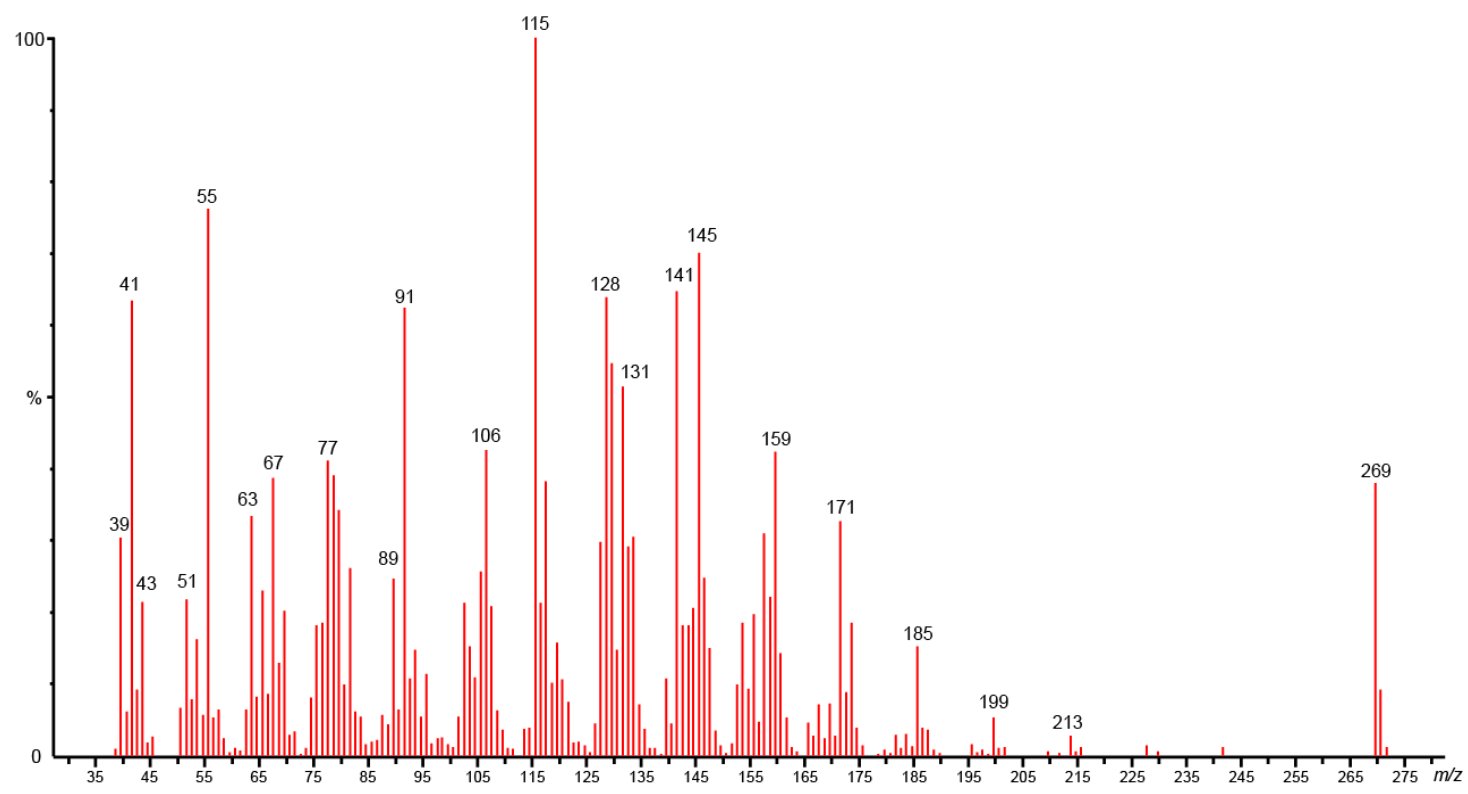

Figure 3. Electronic impact mass spectrum of campestrolide $33(70 \mathrm{eV})$.

A rapid analysis of the ${ }^{1} \mathrm{H}$ - and ${ }^{13} \mathrm{C}-\mathrm{NMR}$ spectra (Figure 4 ) showed the absence of $-\mathrm{CH}_{3}$ groups and the presence of a ketone group (172.98 ppm). Furthermore, the characteristic resonances of a polyacetylene skeleton (constituted by a sequence of two consecutive triple bonds) are identified using the ${ }^{13} \mathrm{C}-\mathrm{NMR}$ spectrum in combination with DEPT data (Table 2).

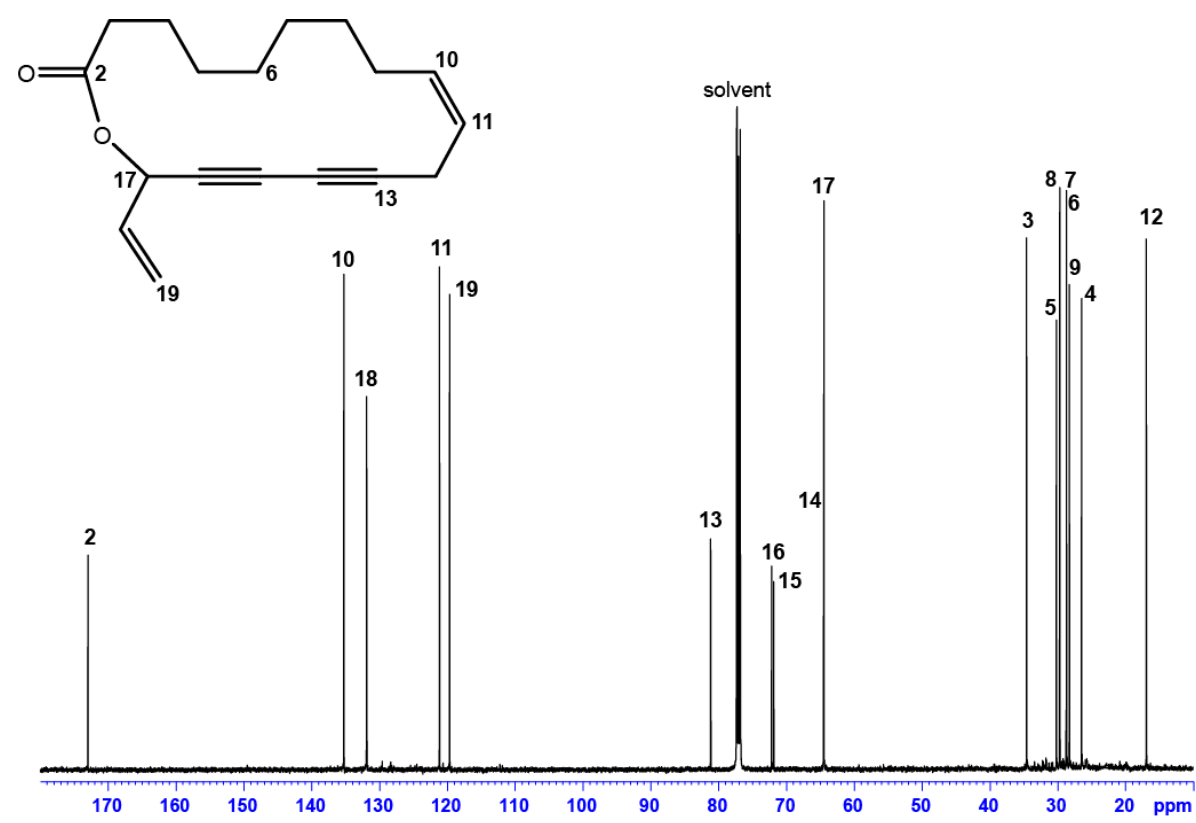

Figure 4. ${ }^{13} \mathrm{C}-\mathrm{NMR}$ spectrum $\left(125.76 \mathrm{MHz}\right.$ in $\left.\mathrm{CDCl}_{3}, 300 \mathrm{~K}\right)$ and structure (inset) of Campestrolide 33 (N.B. NMR signal assignments refer to the numbering of the molecule illustrated on the inset; the stereochemistry of $17-\mathrm{CH}$ would be revealed subsequent to the VCD experiments). 
Table 2. NMR spectroscopic data (500 MHz, $\left.\mathrm{CDCl}_{3}\right)$ for Campestrolide (33).

\begin{tabular}{|c|c|c|c|}
\hline Position & $\delta_{C}$, Type & $\delta_{\mathrm{H}}(\mathrm{J}$ in $\mathrm{Hz})$ & HМBC $^{\text {a }}$ \\
\hline 2 & $172.97, \mathrm{C}$ & - & $3,4,17,18$ \\
\hline 3 & $34.55, \mathrm{CH}_{2}$ & $\begin{array}{l}2.41, \mathrm{~m} \\
2.38, \mathrm{~m}\end{array}$ & 4,5 \\
\hline 4 & $26.45, \mathrm{CH}_{2}$ & $\begin{array}{l}1.76, \mathrm{~m} \\
1.67, \mathrm{~m}\end{array}$ & $3,5,6$ \\
\hline $5^{b}$ & $28.68, \mathrm{CH}_{2}$ & $1.44, \mathrm{~m}$ & $3,4,6,7$ \\
\hline 6 & $29.67, \mathrm{CH}_{2}$ & $1.28, \mathrm{~m}$ & $4,5,7,8$ \\
\hline 7 & $30.17, \mathrm{CH}_{2}$ & $1.36, \mathrm{~m}$ & $5,8,9$ \\
\hline $8^{b}$ & $28.70, \mathrm{CH}_{2}$ & $1.44, \mathrm{~m}$ & $6,7,8$ \\
\hline 9 & $28.26, \mathrm{CH}_{2}$ & $\begin{array}{l}2.10, \mathrm{~m} \\
2.15, \mathrm{~m}\end{array}$ & $8,10,11$ \\
\hline 10 & $135.23, \mathrm{CH}$ & $5.62, \mathrm{~m}$ & $8,9,12$ \\
\hline 11 & $121.13, \mathrm{CH}$ & $5.52, \mathrm{dt}(9.96,7.53)$ & 9,12 \\
\hline 12 & $16.91, \mathrm{CH}_{2}$ & $\begin{array}{l}\text { 2.96, dd }(18.30 ; 7.50) \\
\text { 3.07, dd }(18.30 ; 7.50)\end{array}$ & 10,11 \\
\hline 13 & $81.15, \mathrm{C}$ & - & 11,12 \\
\hline 14 & $64.51, \mathrm{C}$ & - & 12,17 \\
\hline 15 & $71.87, \mathrm{C}$ & - & 12,17 \\
\hline 16 & $72.15, \mathrm{C}$ & - & $12,18,19$ \\
\hline 17 & $64.45, \mathrm{CH}$ & $5.92, \mathrm{~d}(5.85)$ & 18,19 \\
\hline 18 & $131.88, \mathrm{CH}$ & 5.91, ddd $(5.85 ; 10.17 ; 16.90)$ & 17,19 \\
\hline 19 & $119.65, \mathrm{CH}_{2}$ & $\begin{array}{l}\text { 5.37, dd }(16.90 ; 1.2) \\
5.60, \text { dd }(10.17 ; 1.2)\end{array}$ & 18 \\
\hline
\end{tabular}

${ }^{\mathrm{a}} \mathrm{HMBC}$ correlations are from proton(s) stated to the indicated carbon; ${ }^{\mathrm{b}}$ the values could be inverted.

The complete assignment was achieved using the 2D NMR spectra (Figures S1-S3 in the supplementary information with this article). In addition, NOE correlations showed spatial vicinity among the aliphatic chain and the unsaturated part of the molecule, in particular between $3-\mathrm{CH}_{2}$ $\rightarrow 17-\mathrm{CH}$ and $7-\mathrm{CH}_{2} \rightarrow 10-\mathrm{CH}$ (Figure S4). The combination of all spectroscopic data allowed the recognition of a seventeen-atom macrocyclic lactone and its structure is represented below (Figure 4-inset). This unprecedented 17-membered ring lactone, featuring conjugated acetylenic bonds, has been named Campestrolide. Nevertheless, the analytical data do not establish the determination of the absolute configuration of $17-\mathrm{CH}$, which has since been established by vibrational circular dichroism (VCD).

In the last decade, VCD spectroscopy has become a popular technique for the elucidation of absolute configurations of chiral molecules [31-33]. Therefore, in order to determine the stereochemistry of the asymmetrical carbon- 17 of Campestrolide, the VCD spectrum of a sample containing $80 \%$ of compound 33 was measured in $\mathrm{CD}_{2} \mathrm{Cl}_{2}$. Despite the difficulties encountered during the determination of the absolute configuration of a molecule via the VCD spectrum of a mixture, the majority of the measured bands were in good agreement with those obtained by calculation performed on the (Z,S)-enantiomer (region I, II and III in the VCD spectrum-Figure 5a). Moreover, for the same spectral regions, a good accordance is also observed between the experimental IR spectrum recorded for the analyzed sample and the theoretical IR spectrum calculated for the $(Z, S)$-enantiomer (Figure 5b-region I, II and III). This observation reinforces the assignment of these bands to our molecule. Based on the analysis of the spectral data and taking into account the opposite signs between the measured and calculated VCD spectra, we could conclude that the naturally obtained Campestrolide is detected as $(R)$-enantiomer (Figure $5 c$ ), namely (Z)-17(R)-vinyloxacycloheptadeca-10-en-13,15-diyn-2-one. It should be mentioned that the identified configuration is perfectly consistent with those generally reported in the literature for polyacetylenes derivatives [33-35]. 

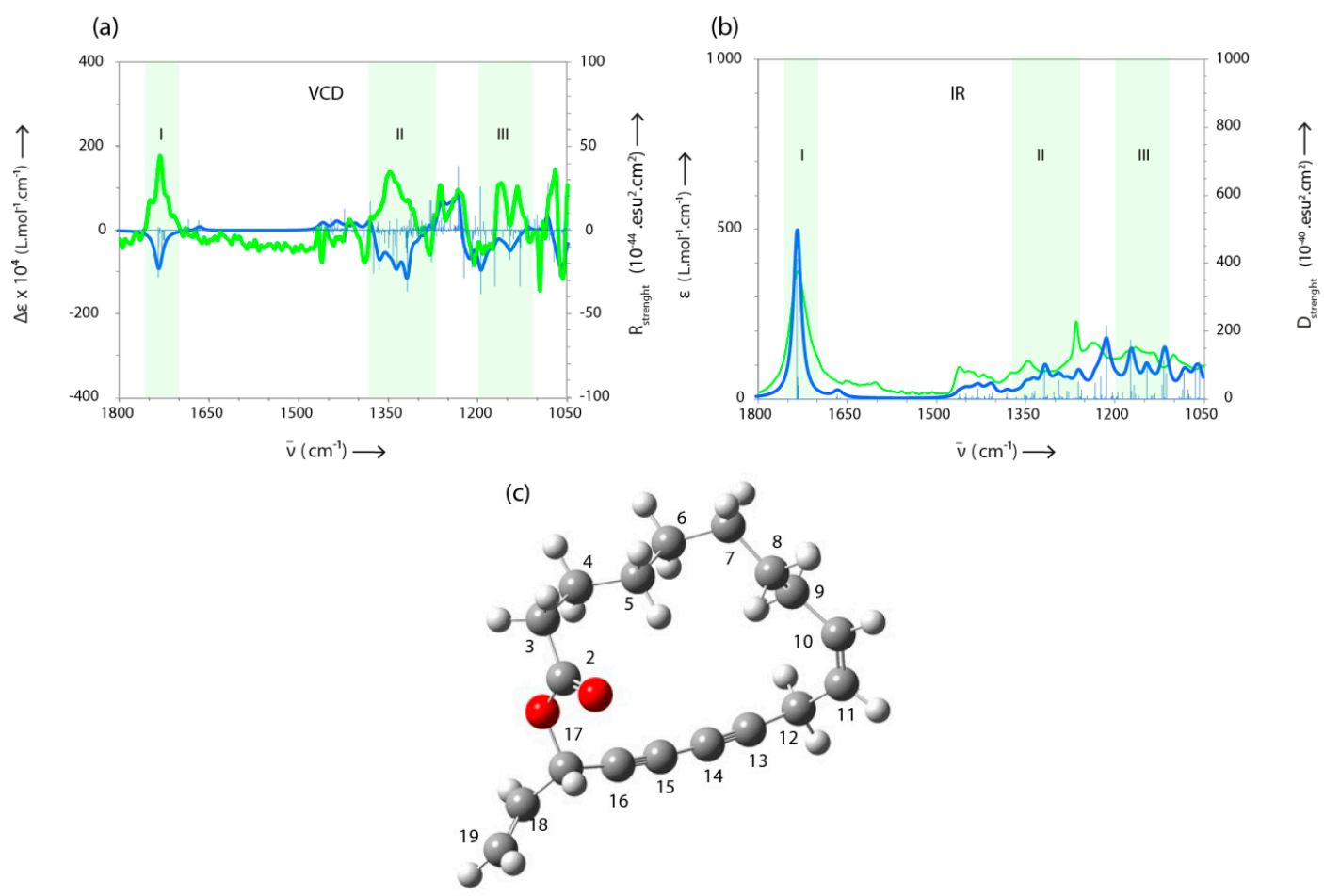

Figure 5. A comparison between the measured (blue) and calculated (green) (a) VCD and (b) IR spectra, respectively; (c) one of the most stable simulated structures of Campestrolide (generated for $(Z, S)$-enantiomer). N.B. Atoms colors: oxygen in red; carbon in gray; hydrogen in white.

To our knowledge, this uncommon natural macrocyclic lactone that includes one cyclo-1,3-diynes motif has only been reported in one other compound (ivorenolide B), which was extracted from Khaya ivorensis - a dicotyledone tree from the Meliaceae family [33,36]. Furthermore, this compound, as well as its 18-memberded ring lactone analogous ivorenolide A, showed significant immunosuppressive activity [33,37-39]. Other macrocyclic lactones (20-membered ring) have been extracted from the marine dinoflagellate Amphidinium species. Researchers have reported cytotoxic properties for all the described amphidinolides mentioned above [40].

\subsection{Biological Activities}

Both the crude hexanic extract of E. campestre and compound 33 were evaluated for their in vitro cytotoxicity and antiprotozoal activities (Table 3). The plant extract showed similar moderate activities $\left(\mathrm{IC}_{50} \approx 4 \mu \mathrm{g} / \mathrm{mL}\right.$ ) on all tested cells and hence, without any selectivity for the concerned parasites. The newly identified macrocyclic lactone was strongly active on Trypanosoma $\left(\mathrm{IC}_{50}=0.6 \mu \mathrm{g} / \mathrm{mL}\right.$ or $2.2 \mu \mathrm{M} \approx 2 \mu \mathrm{M})$, as defined by Beaufay et al. $\left(\mathrm{IC}_{50} \leq 2 \mu \mathrm{M}\right)$ [41], with a reasonable selectivity $(\mathrm{SI}=8.9$ ). As such, it fits the stated criteria for antiparasitic hits [42], i.e., activity in vitro with an $\mathrm{IC}_{50}<1 \mu \mathrm{g} / \mathrm{mL}$ and at least ten-fold higher than on a mammalian cell line. As the calculated campestrolide log $\mathrm{P}$ value ( $\log P=5.56$ ) [43] was close to the one reported for falcarinol ( $\log P=5.50)$ [44], we can assume good membrane permeability of the macrocyclic lactone. Its newly described structure could also be used as a prototype in structure-activity relation studies to improve activity/selectivity. 
Table 3. The cytotoxicity (WI38 and J774), antitrypanosomal (Tbb) and antileishmanial (Lmm) activities expressed in the $\mathrm{IC}_{50}$ (Mean $\pm \mathrm{SD}$ in $\mu \mathrm{g} / \mathrm{mL}$ and $\mu \mathrm{M}$ for pure compounds from at least six values).

\begin{tabular}{|c|c|c|c|c|c|c|}
\hline & \multicolumn{2}{|c|}{ Cytotoxicity } & \multicolumn{2}{|c|}{ Antiparasitic Activity } & \multicolumn{2}{|c|}{ Selectivity Index } \\
\hline & \multicolumn{4}{|c|}{$\mathrm{IC}_{50} \pm \mathrm{SD}$ in $\mu \mathrm{g} / \mathrm{mL}$ ( $\mu \mathrm{M}$ for Pure Compound) } & \multicolumn{2}{|c|}{$\mathrm{IC}_{50} \mathrm{WI} 38 / \mathrm{IC}_{50}$ Parasite } \\
\hline & WI38 & J774 & Tbb & Lmm & Tbb & Lmm \\
\hline Hexanic extract & $4.44 \pm 0.94$ & $4.00 \pm 1.07$ & $3.00 \pm 0.88$ & $3.86 \pm 0.10$ & 1.5 & 1.2 \\
\hline 33 & $\begin{array}{c}5.20 \pm 0.24 \\
(19.24 \pm 0.87)\end{array}$ & $\begin{array}{c}4.84 \pm 0.10 \\
(17.89 \pm 0.35)\end{array}$ & $\begin{array}{c}0.59 \pm 0.08 \\
(2.17 \pm 0.28)\end{array}$ & $\begin{array}{c}3.43 \pm 0.02 \\
(12.67 \pm 0.09)\end{array}$ & 8.9 & 1.5 \\
\hline Positive control & $\begin{array}{c}0.036 \pm 0.022 \\
(0.103 \pm 0.062)^{a}\end{array}$ & $\begin{array}{c}0.007 \pm 0.005 \\
(0.021 \pm 0.013)^{\mathrm{a}}\end{array}$ & $\begin{array}{c}0.031 \pm 0.012 \\
(0.022 \pm 0.008)^{b}\end{array}$ & $\begin{array}{c}0.057 \pm 0.008 \\
(0.097 \pm 0.014)^{\mathrm{c}}\end{array}$ & & \\
\hline
\end{tabular}

WI38: non cancer human fibroblasts; J774: cancerous macrophage-like murine cells; Tbb: Trypanosoma brucei brucei (bloodstream forms); Lmm: Leishmania mexicana mexicana promastigotes; Selectivity index calculated for antiparasitic activities compared to WI38 cytotoxicity. Positive control (reference drug): ${ }^{a}$ camptothecin, ${ }^{\mathrm{b}}$ suramine, ${ }^{c}$ pentamidine.

The antileishmanial or anticancer activities were notable $\left(\mathrm{IC}_{50}=3.4\right.$ and $4.8 \mu \mathrm{M}$, respectively) but not as selective as those observed for the extract. Another well-known complex polyene macrolide is amphotericin $\mathrm{B}\left(\mathrm{IC}_{50}=0.09 \pm 0.06 \mu \mathrm{M}\right)$, a reference drug widely used to treat visceral leishmaniasis but still little studied on cutaneaous one and with dose-limiting toxicity [45]. Some patents are also based on different kinds of macrolides as antiparasitics [46].

Campestrolide can partially explain all the activities observed for the crude extract but it is certainly not the only active component of the mixture, as observed with the other samples containing different percentages of campestrolide (data not shown). Therefore, other components, e.g., the identified polyacetylenes, could influence activities by addition or synergism action. This has already been observed, for example, with the polyphenolic compounds [47]. Indeed, natural polyacetylenes are highly bioactive and reactive phytochemicals and were largely isolated from the Apiaceae family, mostly due to the aliphatic $C_{17}$ chains. Unstable compounds of this variety are known to exhibit some cytotoxic behaviors and an extract, rich in these unsaturated derivatives, has already been shown to possess synergetic cytotoxic activity in combination with taxol [48]. Previous researchers have also shown such compounds to possess encouraging potential against protozoan diseases. However, this requires further investigation [21]. Falcarindiol, another major compound of the crude extract, has yet to be tested for antitrypanosomal and antileishmanial activity. However, Falcarinol, also called panaxynol, was found to be strongly active and selective $\left(\mathrm{IC}_{50}=0.01 \mu \mathrm{g} / \mathrm{mL}\right.$, corresponding to $0.04 \mu \mathrm{M}$, and SI $=858$ ) on Trypanosoma brucei brucei compared to HeLa cytotoxicity. The inhibition of the trypanothione reductase was proposed as one target of this very reactive alkylating agent [49]. Another two natural polyacetylenes, 8-hydroxyheptadeca-1-ene-4,6-diyn-3-yl ethanoate and 16-acetoxy-11-hydroxyoctadeca-17-ene-12,14-diynyl ethanoate, were highly active and selective on Trypanosoma brucei rhodesiense, T. cruzi, Plasmodium falciparum and Leishmania donovani axenic and the infected macrophages amastigotes compared on L6 rat skeletal myoblasts $\left(\mathrm{IC}_{50}=0.1-2.5 \mu \mathrm{M}\right.$. SI $\left.>10\right)$. The terminal methylene double bond seems to improve activity [50].

In addition, germacrene $\mathrm{D}$, another major identified compound, possesses some antiparasitic activity as with other non-lactonized sesquiterpenoids and eudesmanolides, with $61 \%$ growth inhibition of the T. cruzi trypomastigotes at $100 \mu \mathrm{g} / \mathrm{mL}$. It also inhibited cruzain, an essential T. cruzi cysteine protease, with an $\mathrm{IC}_{50}$ of $22.1 \mu \mathrm{g} / \mathrm{mL}$ [21].

Concerning the reported plant extract, dichloromethane and methanol compounds from the aerial parts of the E. campestre displayed antileishmanial activity with $\mathrm{IC}_{50}$ values of 36 and $15 \mu \mathrm{g} / \mathrm{mL}$, respectively, on L. donovani promastigotes. They were inactive on the P. falciparum D6 and W strains [51]. However, the petroleum ether extract exhibited more than 50\% Plasmodium growth inhibition at $4.81 \mu \mathrm{g} / \mathrm{mL}$ [23]. Other Eryngium species have previously shown interesting antiparasitic activities $\left(\mathrm{IC}_{50}<20 \mu \mathrm{g} / \mathrm{mL}\right.$ ) on T. cruzi [50] and L. donovani, but appeared less active or inactive on Plasmodium falciparum $[52,53]$. A daucane sesquiterpene with moderate antileishmanial activity $\left(\mathrm{IC}_{50}\right.$ values of 
14.33 and $7.84 \mu \mathrm{M}$ on L. tarentolae promastigotes and L. donovani amastigotes respectively) was isolated from E. foetidum aerial parts [5].

\section{Materials and Methods}

\subsection{Plant Material}

Aerial parts of Eryngium campestre L. (Apiaceae) were collected in June 2016, from the north-western areas of Algeria. The botanical identification of the plants was performed according to the botanical determination keys summarized in the Flora of Algeria [54] and a voucher specimen has been deposited in the COSNA laboratory (Voucher Code: EC1-06-2016).

\subsection{Extraction}

The dried aerial parts $(120 \mathrm{~g})$ were powdered and weighed, then extracted with hexane $(500 \mathrm{~mL})$ under reflux in a Soxhlet apparatus, at $68^{\circ} \mathrm{C}$. The extract was first filtered on filter paper and then on PTFE filters $(0.2 \mu \mathrm{m})$. After that, the extract was evaporated to dryness under reduced pressure. This resulted in a yield of $1.05 \%$.

\subsection{Compound Identification}

The identification of individual compounds in the E. campestre hexanic extract was carried out using different techniques, such as GC/FID, GC/MS (EI) and 1D and 2D NMR. The identifications were mainly based on comparison of the retention indices (RI) and the MS spectra with those contained in our laboratory library "Arômes". When spectral data were not present in the "Arômes" library, the RI and the MS data were compared with those from commercial libraries [24,55-57]. Compounds absent from consulted libraries were isolated by the fractionation process, using flash column chromatography and then identified mainly by NMR spectroscopy.

\subsection{Fractionation}

We measured $300 \mathrm{mg}$ of the hexanic extract. This was then submitted to chromatography on a silica gel column (200-500 $\mu \mathrm{m}, 4 \mathrm{~g}$, Clarisep ${ }^{\circledR}$ Bonna Agela Technologies, Willington, CT, USA), using an Automatized Combi Flash apparatus (Teledyne ISCO. Lincoln., NE, USA) equipped with a fraction collector and monitored by a UV detector. The solvents of elution were $n$-hexane (A) and diisopropyl ether (B), with a gradients of elution: a (A: 100\%; B: 0\%), b (A: 98\%; B: 2\%), c (A: 96.5\%; B: 3.5\%), d (A: 95\%; B: 5\%), e (A: 90\%; B: 10\%) and f (A: 0\%; B: 100\%).

\subsection{GC-FID Conditions}

Analyses were carried out using a Perkin-Elmer Autosystem XL GC apparatus (Walthon, MA, USA), equipped with a dual flame ionization detection (FID) system and fused-silica capillary columns, namely, Rtx-1 (polydimethylsiloxane) and Rtx-wax (polyethyleneglycol) $(60 \mathrm{~m} \times 0.22 \mathrm{~mm}$ i.d.; of a film thickness of $0.25 \mu \mathrm{m})$. The oven temperature was programmed from 60 to $230{ }^{\circ} \mathrm{C}$ at $2{ }^{\circ} \mathrm{C} / \mathrm{min}$ and then held isothermally at $230^{\circ} \mathrm{C}$ for $35 \mathrm{~min}$ and helium was employed as the carrier gas $(1 \mathrm{~mL} / \mathrm{min})$. The injector and the detector temperatures were maintained at $280{ }^{\circ} \mathrm{C}$ and the samples were injected $(0.2 \mu \mathrm{L}$ of pure oil) in the split mode (1:50). The RI of each compound was determined relative to the retention times of a series of $n$-alkanes (C5-C30) by linear interpolation, using the Van den Dool and Kratz (1963) equation with the aid of the software from Perkin-Elmer (TotalChrom navigator, 6.3.1, Shelton, CT, USA). The relative percentages of the extract constituents were calculated from the GC peak areas by the normalization procedure, without the application of correction factors.

\subsection{GC/MS-EI Conditions}

Samples were analyzed with a Perkin-Elmer Turbo mass detector (quadrupole) coupled to a Perkin-Elmer Autosystem XL, equipped with fused-silica capillary columns Rtx-1 and Rtx-Wax. 
The oven temperature was programmed from 60 to $230{ }^{\circ} \mathrm{C}$ at $2{ }^{\circ} \mathrm{C} / \mathrm{min}$ and then held isothermally at $230{ }^{\circ} \mathrm{C}$ (35 min) and helium was employed as the carrier gas $(1 \mathrm{~mL} / \mathrm{min})$. The following chromatographic conditions were employed: the injection volume was $0.2 \mu \mathrm{L}$ of pure oil; the injector injector temperature was $280{ }^{\circ} \mathrm{C}$; split 1:80; the ion source temperature was $150{ }^{\circ} \mathrm{C}$; the ionization energy was $70 \mathrm{eV}$; the MS (EI) data were acquired over the mass range $35-350 \mathrm{Da}$; and the scan rate was $1 \mathrm{~s}$.

\subsection{NMR Conditions}

NMR experiments were acquired in $\mathrm{CDCl}_{3}$ (EuroIsotop, Saint Aubin, France) at $300 \mathrm{~K}$ using a Bruker Avance DRX 500 NMR spectrometer (Karlsruhe, Germany), operating at 500.13 MHz for ${ }^{1} \mathrm{H}$ and $125.76 \mathrm{MHz}$ for ${ }^{13} \mathrm{C}$ Larmor frequency with a double resonance broadband fluorine observe (BBFO) and $5 \mathrm{~mm}$ probehead. ${ }^{13} \mathrm{C}$-NMR experiments were recorded using the one-pulse excitation pulse sequence $\left(90^{\circ}\right.$ excitation pulse), with ${ }^{1} \mathrm{H}$ decoupling during signal acquisition (performed with WALTZ-16). The relaxation delay was set at $2 \mathrm{~s}$. For each analysed sample, depending on the compound concentration, $3 \mathrm{k}$ up to $5 \mathrm{k}$ free induction decays (FID) $64 \mathrm{k}$ complex data points were collected using a spectral width of $30,000 \mathrm{~Hz}(240 \mathrm{ppm})$. Chemical shifts ( $\delta$ in ppm) were reported relative to the residual signal of $\mathrm{CDCl}_{3}\left(\delta_{\mathrm{C}}=77.04 \mathrm{ppm}\right.$ and $\delta_{\mathrm{H}}=7.26 \mathrm{ppm}$, respectively). Complete ${ }^{1} \mathrm{H}$ and ${ }^{13} \mathrm{C}$ assignments of the requested compounds were obtained using $2 \mathrm{D}$ gradient-selected NMR experiments, ${ }^{1} \mathrm{H}_{-}{ }^{1} \mathrm{H}$ COSY, ${ }^{1} \mathrm{H}-{ }^{13} \mathrm{C}$ HSQC, ${ }^{1} \mathrm{H}_{-}{ }^{13} \mathrm{C}$ HMBC and ${ }^{1} \mathrm{H}_{-}{ }^{1} \mathrm{H}$ NOESY, for which conventional acquisition parameters were used, as described in the literature [58].

\subsection{High-Resolution Mass Spectrometry Experiments}

High-resolution mass spectrometry (HRMS) experiments were performed with a Synapt G2 HDMS quadrupole/time-of-flight (Manchester, UK), equipped with an electrospray source operating in the positive mode, ESI(+). The samples were introduced at a $10 \mu \mathrm{L} \mathrm{min} \mathrm{m}^{-1} \mathrm{flow}$ rate (capillary voltage $+2.8 \mathrm{kV}$, sampling cone voltage $+20 \mathrm{~V}$ under a curtain gas $\left(\mathrm{N}_{2}\right)$, flow of $100 \mathrm{~L} \mathrm{~h}^{-1}$ and heated at $35^{\circ} \mathrm{C}$ ). The samples were dissolved and further diluted in methanol (Sigma-Aldrich, St.-Louis, MO, USA) doped with sodium chloride $(0.1 \mathrm{mM})$ prior to the analysis. Accurate mass experiments were performed using reference ions from an internal calibration procedure, with two reference ions formed upon electrospray of a poly (ethylene oxide) (PEO). Data analyses were conducted using MassLynx 4.1 programs, which were provided by Waters (Manchester, UK).

\subsection{VCD Measurements}

The infrared (IR) and vibrational circular dichroism (VCD) spectra were recorded on a Bruker PMA 50 accessory, coupled to a Vertex 70 Fourier transform infrared spectrometer (Bruker, Wissembourg, Germany). A photoelastic modulator (Hinds PEM 90, Hids Instruments, Portland, OR, USA) set at $1 / 4$ retardation was used to modulate the handedness of the circular polarized light at $50 \mathrm{kHz}$. Demodulation was performed by a lock-in amplifier (SR830 DSP, Zurich Instruments, Zurich, Switzerland). An optical low-pass filter $\left(<1800 \mathrm{~cm}^{-1}\right)$ was used to enhance the signal/noise ratio before use of the photoelastic modulator. A transmission cell of $200 \mu \mathrm{m}$ optical pathlength, equipped with $\mathrm{CaF}_{2}$ windows, was used. The solutions with a concentration of $0.1 \mathrm{~mol} \mathrm{~L}-1$ were prepared by dissolving the solid samples in $\mathrm{CD}_{2} \mathrm{Cl}_{2}$. The VCD spectrum of the enantiomer was measured at room temperature using a sample with an estimated purity of $80 \%$. The baseline of the VCD spectrum was corrected by the subtraction of the VCD spectrum of the solvent. For each individual spectrum, about 16,000 scans were averaged at $4 \mathrm{~cm}^{-1}$ resolution (corresponding to $4 \mathrm{~h}$ of measurement time). For the IR absorption spectra, the cell filled with $\mathrm{CD}_{2} \mathrm{Cl}_{2}$ served as a reference. The spectra are presented without any smoothing and further data processing.

The calculation of the VCD and IR spectra was performed on the (S)-enantiomer of compound 33 using Gaussian 16 package [59]. The geometry optimizations, vibrational frequencies, IR absorption, and VCD intensities were calculated with the Density Functional Theory (DFT) using the B3LYP 
functional combined with the 6-311G $(\mathrm{d}, \mathrm{p})$ basis set. The average solvent $\left(\mathrm{CH}_{2} \mathrm{Cl}_{2}\right)$ effects have been introduced using the implicit solvation model, SMD, which is based on the integral equation formalism of the polarizable continuum model (ief-pcm). The computed harmonic frequencies are generally larger than the fundamentals observed experimentally. They were calibrated using a scaling factor of 0.98 . The IR absorption and the VCD spectra were constructed from the calculated dipole and the rotational strengths assuming the Lorentzian band shape with a half-width at a half-maximum of $8 \mathrm{~cm}^{-1}$. The computational method is detailed in the supplementary information with this article.

\subsection{Biological Assays}

The crude extract and the newly identified pure compound (91.9\%), campestrolide, were evaluated in vitro for their cytotoxicity on two mammalian cell lines: normal human fibroblasts (WI38) and cancerous macrophage-like murine cells. Their antiprotozoal activities were also investigated on Trypanosoma brucei brucei (Tbb. strain 427) bloodstream forms and Leishmania mexicana mexicana (Lmm. MHOM/BZ/84/BEL46) promastigotes. The tests were performed using [60,61] stock solutions prepared in DMSO at $10 \mathrm{mg} / \mathrm{mL}$. For the cytotoxicity assay, the samples were tested in eight serial 1.7-fold dilutions ( $150 \mu \mathrm{L}$ transferred into $100 \mu \mathrm{L}$ fresh medium) in the 96-well microtiter plates (concentration range: 0.7-25 $\mathrm{gg} / \mathrm{mL}$ ). The camptothecin (Sigma-Aldrich, St.-Louis, MO, USA) was used as a positive control with 5-fold dilutions (concentration range: $0.00032-25 \mu \mathrm{g} / \mathrm{mL}$ ) from a $10 \mathrm{mg} / \mathrm{mL}$ DMSO stock solution. For the antiparasitic assays, the samples were tested in eight serial 2-fold dilutions (concentration range: $0.20-25$ or $0.10-12 \mu \mathrm{g} / \mathrm{mL}$ on Leishmania and Trypanosoma, respectively). Suramine sodium and pentamidine isethionate salts (Sigma-Aldrich, St.-Louis, MO, USA) were used as a positive control with 3-fold dilutions $(0.0046-10 \mu \mathrm{g} / \mathrm{mL})$ from a stock solution of $2 \mathrm{mg} / \mathrm{mL}$ as well as amphotericin B. A maximum of $0.5 \%$ DMSO was previously verified to be non-toxic in all the biological assays. The $\mathrm{IC}_{50}$ values were determined using Microsoft Excel and GraphPad Prism 7.0 software (GraphPad, San Diego, CA, USA), based on a nonlinear regression. The selectivity index was calculated in comparison to the WI38 cytotoxicity to assess the therapeutic properties as antiparasitic or anticancer hits.

\section{Conclusions}

A new uncommon macrocyclic lactone named campestrolide, along with other known compounds, was isolated and identified in the Eryngium campestre hexane crude extract. This newly described compound presents a particular structure that is composed of a rigid 1,3-dynes motif and a flexible aliphatic part. Moreover, campestrolide possesses relatively strong antitrypanosomal activity but moderate selectivity. Therefore, we assume that campestrolide could be considered for further investigation to improve activity/selectivity. Furthermore, it is partially responsible for the observed antiprotozoal activities and cytotoxicity in the crude extract.

Supplementary Materials: The following are available online: 1H-NMR spectrum and 2D-NMR data of campestrolide, computational details, enthalpies and Boltzmann populations of calculated conformations, and additional comparison between calculated and experimental IR and VCD data.

Author Contributions: A.M. (Alain Muselli), A.T., J.Q.-L. and C.B. conceived and designed the experiments. A.M. (Ali Medbouhi), A.T., C.B. and J.-V.N. performed the experiments. A.M. (Ali Medbouhi), A.M. (Alain Muselli), J.Q.-L, C.B. and A.T. wrote the manuscript. N.D. and J.C. revised the manuscript. All authors read and approved the final manuscript.

Funding: This research received no external funding.

Acknowledgments: A.M. (Ali Mehboudi) is indebted to the Ministère des Affaires Etrangères et du Développement International for the research grant (Campus France, Programme d'Excellence Eiffel) and to the Ministère de l'Europe et des Affaires Etrangères for the research grant (PROFAS B+). A.T. acknowledges support from Spectropole, the Analytical Facility of Aix Marseille University, for allowing a special access to the instruments purchased with the European Funding (FEDER OBJ2142-3341).

Conflicts of Interest: The authors declare that there is no conflict of interest. 


\section{References}

1. Wörz, A. A new subgeneric classification of the genus Eryngium L. (Apiaceae, Saniculoideae). Bot. Jahrb. Syst. 2005, 126, 253-259. [CrossRef]

2. Wang, P. Phytochemical constituents and pharmacological activities of eryngium 1. (Apiaceae). Pharm. Crop. 2012, 3, 99-120. [CrossRef]

3. Moerman, D.E. Native American Food Plants. An Ethnobotanical Dictionary; Timber Press Inc.: London, UK, 2011; p. 65.

4. Suciu, S.; Pârvu, A.E. Comparative Study on the Effects of Eryngium Sp. Extracts in an Acute Inflammation Model in Rat. Annals RSCB 2012, 17, 86-91.

5. Rojas-Silva, P.; Graziose, R.; Vesely, B.; Poulev, A.; Mbeunkui, F.; Grace, M.H.; Kyle, D.E.; Lila, M.A.; Raskin, I. Leishmanicidal activity of a daucane sesquiterpene isolated fromeryngium foetidum. Pharm. Biol. 2014, 52, 398-401. [CrossRef]

6. Jaghabir, M. Hypoglycemic effects of Eryngium creticum. Arch. Pharm. Res. 1991, 14, 295-297. [CrossRef]

7. Goleniowski, M.E.; Bongiovanni, G.; Palacio, L.; Nuñez, C.; Cantero, J. Medicinal plants from the 'Sierra de Comechingones', Argentina. J. Ethnopharmacol. 2006, 107, 324-341. [CrossRef] [PubMed]

8. Coste, H. Flore Descriptive et Illustrée de la France, de la Corse et des Contrées Limitrophes II; Librairie Scientifique et Technique Albert Blanchart: Le Val-Saint-Germain, France, 1980.

9. Pieroni, A.; Pardo-de-Santayana, M.; Firenzuoli, F.; Quave, C.L. The european heritage of folk medicines and medicinal foods: Its contribution to the cams of tomorrow. Evid.-Based Complement. Altern. Med. 2013, 2013, 1-2. [CrossRef]

10. Kartnig, T.; Wolf, J. Flavonoids from the Aboveground Parts of Eryngium campestre. Planta Med. 1993, 58, 285. [CrossRef]

11. Abou El-Kassem, L.; Hawas, U.; Awad, H.; Taie, H. Flavonoids from the aerial parts of eryngium campestre 1. with antioxidant and anti-alzheimer activities. Planta Medica 2013, 79. [CrossRef]

12. Hohmann, J.; Páll, Z.; Günther, G.; Máthé, I. Flavonolacyl glycosides of the aerial parts of eryngium campestre. Planta Medica 1997, 63, 96. [CrossRef]

13. Erdelmeier, C.A.J.; Sticher, O. A cyclohexenone and a cyclohexadienone glycoside from eryngium campestre. Phytochemistry 1986, 25, 741-743. [CrossRef]

14. Erdelmeier, C.; Sticher, O. Coumarin derivatives from eryngium campestre 1. Planta Med. 1985, 51, 407-409. [CrossRef]

15. Kartal, M.; Mitaine-Offer, A.-C.; Abu-Asaker, M.; Miyamoto, T.; Calis, I.; Wagner, H.; Lacaille-Dubois, M.-A. Two new triterpene saponins from eryngium campestre. Chem. Pharm. Bull. 2005, 53, 1318-1320. [CrossRef]

16. Abd-Elmonem, A.R.; Shehab, N. Study of the volatile oil of Eryngium campestre 1. growing in Egypt. G. Bull. Fac. Pharm. Cairo Univ. 2008, 44, 3379-3388.

17. Pala-Paul, J.; Usano-Alemany, J.; Soria, A.C.; Perez-Alonso, M.J.; Brophy, J.J. Essential oil composition of Eryngium campestre L. growing in different soil types. A preliminary study. Nat. Prod. Commun. 2008, 3, 1121-1126.

18. Usta, C.; Yildirim, A.B.; Turker, A.U. Antibacterial and antitumour activities of some plants grown in turkey. Biotechnol. Biotechnol. Equip. 2014, 28, 306-315. [CrossRef] [PubMed]

19. Hawas, U.W.; El-Kassem, L.A.T.; Awad, H.M.; Taie, H.A.A. Anti-Alzheimer, Antioxidant Activities and Flavonol Glycosides of Eryngium campestre L. Curr. Chem. Biol. 2013, 7, 188-195. [CrossRef]

20. Küpeli, E.; Kartal, M.; Aslan, S.; Yesilada, E. Comparative evaluation of the anti-inflammatory and antinociceptive activity of turkish eryngium species. J. Ethnopharmacol. 2006, 107, 32-37. [CrossRef]

21. Schmidt, T.J.; Khalid, S.; Romanha, A.; Alves, T.; Biavatti, M.; Brun, R.; Da Costa, R.; De Catsro, S. The potential of secondary metabolites from plants as drugs or leads against protozoan neglected diseases-part II. Curr. Med. Chem. 2012, 19, 2128-2175. [CrossRef]

22. Franco Minguel, J.R. Report of the Second WHO Stakeholders Meeting on Rhodesiense Human African Trypanosomiasis; WHO/Department of Control of Neglected Tropical Diseases: Genève, Switzerland, 2017.

23. Zimmermann, S.; Thomi, S.; Kaiser, M.; Hamburger, M.; Adams, M. Screening and HPLC-Based Activity Profiling for New Antiprotozoal Leads from European Plants. Sci. Pharm. 2012, 80, 205-213. [CrossRef]

24. Joulain, D.; König, W.A. The Atlas of Spectral Data of Sesquiterpene Hydrocarbons; E.B.-Verlag: Hamburg, Germany, 1998. 
25. Nitz, S.; Spraul, M.-H.; Drawert, F. C17 Polyacetylenic alcohols as the major constituents in roots of Petroselinum crispum Mill. ssp. tuberosum. J. Agric. Food Chem. 1990, 38, 1445-1447. [CrossRef]

26. Fujioka, T.; Furumi, K.; Fujii, H.; Okabe, H.; Mihashi, K.; Nakano, Y.; Matsunaga, H.; Katano, M.; Mori, M. Antiproliferative Constituents from Umbelliferae Plants. V. A New Furanocoumarin and Falcarindiol Furanocoumarin Ethers from the Root of Angelica japonica. Chem. Pharm. Bull. 1999, 47, 96-100. [CrossRef] [PubMed]

27. Dawid, C.; Dunemann, F.; Schwab, W.; Nothnagel, T.; Hofmann, T. Bioactive C17-Polyacetylenes in Carrots (Daucus carota L.): Current Knowledge and Future Perspectives. J. Agric. Food Chem. 2015, 63, 9211-9222. [CrossRef]

28. Bohlmann, F.; Zdero, C. Terpene derivatives from higher plants, XII. On new terpene aldehyde esters from Eryngium species. Chem. Ber. 1971, 104, 1957-1961. [CrossRef]

29. Jin, H.R.; Zhao, J.; Zhang, Z.; Liao, Y.; Wang, C.-Z.; Huang, W.-H.; Li, S.-P.; He, T.-C.; Yuan, C.-S.; Du, W. The antitumor natural compound falcarindiol promotes cancer cell death by inducing endoplasmic reticulum stress. Cell Death Dis. 2012, 3, e376. [CrossRef] [PubMed]

30. Meot-Duros, L.; Cérantola, S.; Talarmin, H.; Le Meur, C.; Le Floch, G.; Magné, C. New antibacterial and cytotoxic activities of falcarindiol isolated in crithmum maritimum 1. leaf extract. Food Chem. Toxicol. 2010, 48, 553-557. [CrossRef]

31. Batista, A.N.L.; dos Santos, F.M., Jr.; Batista, J.M., Jr.; Cass, Q.B. Enantiomeric Mixtures in Natural Product Chemistry: Separation and Absolute Configuration Assignment. Molecules 2018, 23, 492. [CrossRef]

32. Said, M.E.-A.; Bombarda, I.; Naubron, J.-V.; Vanloot, P.; Jean, M.; Cheriti, A.; Dupuy, N.; Roussel, C. Isolation of the major chiral compounds from Bubonium graveolens essential oil by HPLC and absolute configuration determination by VCD. Chirality 2017, 29, 70-79. [CrossRef]

33. Ungeheuer, F.; Fürstner, A. Concise Total Synthesis of Ivorenolide B1. Chem.-Eur. J. 2015, 21, 11387-11392. [CrossRef] [PubMed]

34. Zidorn, C.; Jöhrer, K.; Ganzera, M.; Schubert, B.; Sigmund, E.M.; Mader, J.; Greil, R.; Ellmerer, E.P.; Stuppner, H. Polyacetylenes from the apiaceae vegetables carrot, celery, fennel, parsley, and parsnip and their cytotoxic activities. J. Agric. Food Chem. 2005, 53, 2518-2523. [CrossRef] [PubMed]

35. Ratnayake, A.S.; Hemscheidt, T. Olefin Cross-Metathesis as a Tool in Natural Product Degradation. The Stereochemistry of (+)-Falcarindiol. Org. Lett. 2002, 4, 4667-4668. [CrossRef] [PubMed]

36. Wang, Y.; Liu, Q.-F.; Xue, J.-J.; Zhou, Y.; Yu, H.-C.; Yang, S.-P.; Zhang, B.; Zuo, J.-P.; Li, Y.; Yue, J.M. Ivorenolide $\mathrm{B}$, an Immunosuppressive 17-Membered Macrolide from Khaya ivorensis: Structural Determination and Total Synthesis. Org. Lett. 2014, 16, 2062-2065. [CrossRef] [PubMed]

37. Zhang, B.; Wang, Y.; Yang, S.-P.; Zhou, Y.; Wu, W.-B.; Tank, W.; Zuo, J.-P.; Li, Y.; Yue, J.M. Ivorenolide A, an Unprecedented Immunosuppressive Macrolide from Khaya ivorensis: Structural Elucidation and Bioinspired Total Synthesis. J. Am. Chem. Soc. 2012, 134, 20605-20608. [CrossRef] [PubMed]

38. Tsuda, M.; Oguchi, K.; Iwamoto, R.; Okamoto, Y.; Fukushi, E.; Kawabata, J.; Ozawa, T.; Masuda, A. Iriomoteolides-1b and -1c, 20-Membered Macrolides from a Marine Dinoflagellate Amphidinium Species. J. Nat. Prod. 2007, 70, 1661-1663. [CrossRef]

39. Tsuda, M.; Izui, N.; Shimbo, K.; Sato, M.; Fukushi, E.; Kawabata, J.; Kobayashi, J. Amphidinolide Y, a Novel 17-Membered Macrolide from Dinoflagellate Amphidinium sp.: Plausible Biogenetic Precursor of Amphidinolide X. J. Org. Chem. 2003, 68, 9109-9112. [CrossRef] [PubMed]

40. Kobayashi, J. Amphidinolides and Its Related Macrolides from Marine Dinoflagellates. J. Antibiot. 2008, 61, 271-284. [CrossRef] [PubMed]

41. Beaufay, C.; Bero, J.; Quetin-Leclercq, J. Antimalarial Terpenic Compounds Isolated from Plants Used in Traditional Medicine (2010-July 2016). In Natural Antimicrobial Agents. Sustainable Development and Biodiversity; Mérillon, J.M., Riviere, C., Eds.; Springer: Cham, Switzerland, 2018; Volume 19, pp. 247-268.

42. Pink, R.; Hudson, A.; Mouriès, M.-A.; Bendig, M. Opportunities and challenges in antiparasitic drug discovery. Nat. Rev. Drug Discov. 2005, 4, 727-740. [CrossRef]

43. Molinspiration Cheminformatics, Nova ulica, SK-900 26 Slovensky Grob, Slovak Republic. Available online: http:/ / www.molinspiration.com/cgi-bin/properties (accessed on 23 October 2018).

44. U.S. National Library of Medicine. National Center for Biotechnology Information. Available online: https: / / pubchem.ncbi.nlm.nih.gov/ compound/332\#section=Chemical-and-Physical-Properties (accessed on 23 October 2018). 
45. Balasegaram, M.; Ritmeijer, K.; Lima, M.; Burza, S.; Genovese, G.; Milani, B.; Gaspani, S.; Potet, J.; Chappuis, F. Liposomal amphotericin B as a treatment for human leishmaniasis. Expert Opin. Emerg. Drugs 2012, 17, 493-510. [CrossRef]

46. Fountain, M.W.; Weiss, S.J.; Lenk, R.P.; Propescu, M.C.; Ginsberg, R.S. Enhancement of Pharmaceutical Activity. U.S. Patent 5000958, 26 July 1984.

47. Brglez Mojzer, E.; Knez Hrncic, M.; Škerget, M.; Knez, Z.; Bren, U. Polyphenols: Extraction Methods, Antioxidative Action, Bioavailability and Anticarcinogenic Effects. Molecules 2016, 21, 901. [CrossRef]

48. Cheung, S.S.C.; Tai, J.; Hasman, D.; Ou, D.; Warnock, G.L. Inhibition of Human Pancreatic Cancer Cell Proliferation by Devil's Club Oplopanax horridus and Its Polyacetylene Bioactive Compound. Nutr. Cancer 2015, 67, 954-964. [CrossRef]

49. Herrmann, F.; Sporer, F.; Tahrani, A.; Wink, M. Antitrypanosomal Properties of Panax ginseng C. A. Meyer: New Possibilities for a Remarkable Traditional Drug. Phytother. Res. 2013, 27, 86-98. [CrossRef] [PubMed]

50. Senn, M.; Gunzenhauser, S.; Brun, R.U.; Séquin, U. Antiprotozoal polyacetylenes from the Tanzanian medicinal plant Cussonia zimmermannii. J. Nat. Prod. 2007, 70, 1565-1569. [CrossRef] [PubMed]

51. Fokialakis, N.; Kalpoutzakis, E.; Tekwani, B.L.; Khan, S.I.; Kobaisy, M.; Skaltsounis, A.L.; Duke, S.O. Evaluation of the antimalarial and antileishmanial activity of plants from the Greek island of Crete. J. Nat. Med. 2007, 61, 38-45. [CrossRef]

52. Molina-Garza, Z.J.; Bazaldúa-Rodríguez, A.F.; Quintanilla-Licea, R.; Galaviz-Silva, L. Anti-Trypanosoma cruzi activity of 10 medicinal plants used in northeast Mexico. Acta Trop. 2014, 136, 14-18. [CrossRef]

53. Roumy, V.; Garcia-Pizango, G.; Gutierrez-Choquevilca, A.L.; Ruiz, L.; Jullian, V.; Winterton, P.; Fabre, N.; Moulis, C.; Valentin, A. Amazonian plants from Peru used by Quechua and Mestizo to treat malaria with evaluation of their activity. J. Ethnopharmacol. 2007, 112, 482-489. [CrossRef] [PubMed]

54. Quézel, P.; Santa, S. Nouvelle Flore de l'Algérie et des Régions Désertiques Méridionales; Éditions du Centre national de la Recherche scientifique: Paris, France, 1962.

55. Adams, R.P. Identification of Essential Oil Components by Gas Chromatography/Mass Spectrometry, 4th ed.; Allured Publishing Corporation: Carol Stream, IL, USA, 2007.

56. National Institute of Standards and Technology. NIst webBook. 2015. Available online: http://webbook.nist. gov/chemistry/ (accessed on 24 January 2017).

57. König, W.A.; Joulain, D.; Hochmuth, D.H. Terpenoids and Related Constituents of Essential Oils, Library of Mass Finder 2.1; Institute of Organic Chemistry, University of Hamburg: Hamburg, Germany, 2011.

58. Braun, S.; Kalinowski, H.-O.; Berger, S. 150 and More Basic NMR Experiments. A Practical Course; Wiley-VCH: Weinheim, Germany, 1998.

59. Frisch, M.J.; Trucks, G.W.; Schlegel, H.B.; Scuseria, G.E.; Robb, M.A.; Cheeseman, J.R.; Scalmani, G.; Barone, V.; Petersson, G.A.; Nakatsuji, H.; et al. Gaussian 16; Revision A.03; Barone, V., Petersson, G.A., Nakatsuji, H., Eds.; Gaussian, Inc.: Wallingford, CT, USA, 2016.

60. Hoet, S.; Stévigny, C.; Block, S.; Opperdoes, F.; Colson, P.; Baldeyrou, B.; Lansiaux, A.; Bailly, C.; Quetin-Leclercq, J. Alkaloids from Cassytha filiformis and related aporphines: Antitrypanosomal activity, cytotoxicity, and interaction with DNA and topoisomerases. Planta Med. 2004, 70, 407-413. [CrossRef] [PubMed]

61. Le, T.B.; Beaufay, C.; Nghiem, D.T.; Mingeot-Leclercq, M.-P.; Quetin-Leclercq, J. In Vitro Anti-Leishmanial Activity of Essential Oils Extracted from Vietnamese Plants. Molecules 2017, 22, 1071. [CrossRef]

Sample Availability: Samples of the compounds 32, 33 and 34 are available from the authors. 